\title{
Stress: A Risk Factor For Psoriasis, Vitiligo And Alopecia Areata
}

\author{
L Qassim Al-Rubaiy, K Al-Rubiay
}

\section{Citation}

L Qassim Al-Rubaiy, K Al-Rubiay. Stress: A Risk Factor For Psoriasis, Vitiligo And Alopecia Areata. The Internet Journal of Dermatology. 2005 Volume 4 Number 2.

DOI: $\underline{10.5580 / 248 \mathrm{e}}$

\begin{abstract}
Background: The possibility of a influence of stress especially of stressful life events on the course of various skin diseases has long been postulated.

Objectives: The aim of this study was to determine the effect of stressful life events on the onset and on the state of the psoriasis, vitiligo and alopecia areata.
\end{abstract}

Design: The design of study was case-control study.

Setting: Cases and controls were selected from Basrah General Hospital (BGH), Sadder Teaching Hospital (STH) and private clinic of dermatology (P.C) in Basra, Iraq.

Methods: The total number of cases was 283 patients in which of psoriasis. vitiligo and alopecia areata constituted 98,87 and 98 patients respectively while total number of controls was 242 patients have dermatological diseases other than cases. All cases and controls were matched on the bases of their similarity with respect to age and sex.

Results: The influence of stress factor have been postulated on the course of psoriasis, vitiligo and alopecia areata . High percentage of patients with vitiligo (54.0\%) and alopecia areata $(62.2 \%)$ mentioned stress as cause of their disease. Statistically this was significant for vitiligo $(P=0.01708)$ and highly significant for alopecia areata $(P=0.00012)$ but not on psoriasis ( $p=0.656)$. It was also found that stress made the state of disease worse only to be highly significant in psoriasis $(P=0.00288)$ and significant in alopecia areata $(P=0.02141), O R=1.739$ and $95 \% \mathrm{Cl}$ of $O R=1.08-2.79)$ but not on vitiligo $(p=0.10589)$.

Conclusion: The study confirmed that significant association were detected between stress factor and each of psoriasis, vitiligo and alopecia areata

\section{INTRODUCTION}

The clinical wisdom and experience, as well as many observations and studies support the possibility of an influence of stress events on the course of many skin diseases. The role of stressful life events in triggering or exacerbating of vitiligo, psoriasis, and alopecia areata was apparently clearer $\left[{ }_{1,2}, 3,4,5,6,7,8\right]$. Nevertheless, the specific pathogenic role of psychological stress remains unknown $\left[9,10,{ }_{11}, 1_{2}\right]$.

Several studies assessing stressful life events have been conducted and seem to confirm that stress may trigger the disease. The early onset of psoriasis ( $<40$ years ) was associated more frequently with psychological factors, such as stress $\left[{ }_{2,5,6}\right]$. Patients with skin diseases stating that their disease worsened at time of psychological stress $\left[{ }_{2}, 3,4,9\right]$.

A recent studies which measured the frequency and number of stressful life events occurring over a specified period among vitiligo and alopecia areata suggested that such patients endured a significantly higher number of stressful life events than do controls suggesting that psychological distress may have contributed to the onset of vitiligo and alopecia areata $\left[{ }_{7}, 8\right]$. Much clinical evidence suggests that the 
nervous system, including psychological factors, can influence the course of alopecia areata $\left[{ }_{10},{ }_{11}\right]$. This effect may be mediated by corticotropin-releasing hormone (CRH) released locally in the skin from dorsal root ganglia or immune cell leading to intense local inflammation $\left.{ }_{12}\right]$.

\section{PATIENTS AND METHODS}

The eligibility criteria required for diagnosis of cases and controls in our study consist of combination of symptoms and signs. Cases and controls were selected from Department of dermatology of Basrah General Hospital and Sadder Teaching Hospital also from private clinic. All cases and controls were matched on the bases of their similarity with respect to age and sex. The total number of cases was 283 patients of which psoriasis, vitiligo and alopecia areata constituted 98,87 and 98 patients respectively while total number of controls was 242 patients have skin diseases other than in the cases.

The information were obtained through direct communication by personal interview. The result were represented in simple tables and for the purpose of estimation of risk it was carried out by calculation of $\mathrm{X} 2, \mathrm{OR}$, and $95 \% \mathrm{CI}$ of OR.

\section{RESULTS}

The total number of cases was 283 patients 137 (48.4\%) were males and $146(51.6 \%)$ were females, while controls were 242 patients, 116 ( 47.9) were females and 126 ( 52.1 $\%$ ) were females [Table-1 ]. The commonest skin diseases of controls were bacterial infections 47 (19.4\%) followed by dermatitis/ eczema $30(12.4 \%)$.

\section{Figure 1}

Table 1: The distribution of cases and controls according to their sources and sex.

\begin{tabular}{|c|c|c|c|c|c|c|}
\hline \multirow[t]{2}{*}{ Cases } & \multicolumn{3}{|c|}{ Sources * } & \multicolumn{2}{|l|}{ Sex } & \multirow[t]{2}{*}{ Total } \\
\hline & $\mathrm{BGH}$ & STH & PV & Males & Females & \\
\hline Psoriasis & 45 & 24 & 29 & 47 & 51 & 98 \\
\hline Vitiligo & 36 & 19 & 32 & 41 & 46 & 87 \\
\hline Alopecia areata & 34 & 24 & 40 & 49 & 49 & 98 \\
\hline Total & 115 & 67 & 101 & $137(48.4)$ & $146(51.6)$ & 283 \\
\hline Controls & 112 & 59 & 71 & $116(47.9)$ & $126(52.1)$ & 242 \\
\hline
\end{tabular}

"BGH -Basrah General Hospital

*STH- Sadder Teaching Hospital

"PV - Private clinic

High percentage of patients with vitiligo (54.0\%) and alopecia areata (62.2\%) mentioned stress as cause of their disease. Statistically this was significant for vitiligo $(\mathrm{P}=$ $0.01708, \mathrm{OR}=1.818$ and $95 \% \mathrm{Cl}$ of $\mathrm{OR}=1.11-2.98$ ) and highly significant for alopecia areata $(\mathrm{P}=0.00012, \mathrm{OR}=$ 2.551 , and $95 \% \mathrm{C} 1$ of $\mathrm{OR}=1.57-4.14)$, but not on psoriasis $(\mathrm{p}=0.65999, \mathrm{OR}=1.113, \mathrm{CI}=0.69-1.79)$ [Table $2 \mathrm{I}$.

\section{Figure 2}

Table 2: The frequency of stress factor as a cause of disease according to patients perception among cases and controls .

\begin{tabular}{|c|c|c|c|c|c|c|c|c|}
\hline \multirow[t]{2}{*}{ Stess } & \multicolumn{2}{|c|}{ psoriasis } & \multicolumn{2}{|c|}{ vitiligo } & \multicolumn{2}{|c|}{ Alopecia areata } & \multicolumn{2}{|c|}{ controls } \\
\hline & No. & $\%$ & No & $\%$ & No. & $\%$ & No. & $\%$ \\
\hline Yes & 41 & 41.8 & 47 & 54.0 & 61 & 62.2 & 95 & 39.3 \\
\hline No & 57 & 58.2 & 40 & 46.0 & 37 & 37.8 & 147 & BD. 7 \\
\hline$x^{2}$ & \multicolumn{2}{|c|}{0.19345} & \multicolumn{2}{|c|}{5.68817} & \multicolumn{2}{|c|}{14.8459} & & \\
\hline $\mathrm{P}$ & \multicolumn{2}{|c|}{0.65999} & \multicolumn{2}{|c|}{0.01708} & \multicolumn{2}{|c|}{0.00012} & & \\
\hline OR* & \multicolumn{2}{|c|}{1.113} & \multicolumn{2}{|c|}{1818} & \multicolumn{2}{|c|}{2.551} & & \\
\hline $95 \% \mathrm{Cl}^{* *}$ & \multicolumn{2}{|c|}{$0.69-1.79$} & \multicolumn{2}{|c|}{$1.11-2.98$} & \multicolumn{2}{|c|}{$1.57-4.14$} & & \\
\hline
\end{tabular}

It was found that stress made the state of disease worse only to be highly significant in psoriasis $(\mathrm{P}=0.00288$, OR-2.049 and $95 \% \mathrm{CI}$ of $\mathrm{OR}=1.27-3.30)$ and significant in alopecia areata $(\mathrm{P}=0.02141, \mathrm{OR}=1.739$ and $95 \% \mathrm{CI}$ of $\mathrm{OR}=1.08$ -2.79) but not on vitiligo $(\mathrm{P}=0.10589, \mathrm{OR}=0.646, \mathrm{CI}=0.38$ -1.1) [Table -3 ].

\section{Figure 3}

Table 3: The distribution of cases and controls according to effect of stress on the state of the skin diseases

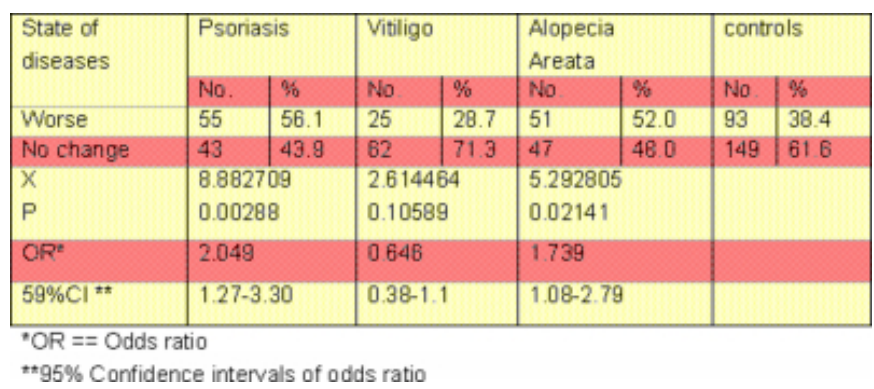

\section{DISCUSSION}

There are multiple risk factors for most of skin diseases and often the risk factors are correlated with each other. Casecontrol is one of the analytic epidemiological method to test risk factors with respect to the occurrence of specific diseases $\left[{ }_{13}\right]$.

The study showed that $54 \%$ of patient with vitiligo and $62.2 \%$ of patient with alopecia areata mentioned that stress was a cause of their disease with significant difference. Also it was showed that $56.1 \%$ of psoriasis and $52.0 \%$ of alopecia areata patients reported that the state of their diseases became worse which was statistically significant. Our result

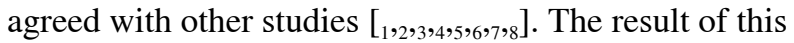
study was consistent with previous studies which suggested that stress may be an important precipitating factors in onset 
or in exacerbation of alopecia areata $\left[{ }_{8}, 10,11,1_{12}\right]$.

According to patient consideration $54 \%$ of patients with vitiligo claimed stress as a cause of the disease. This finding consistent with a retrospective study in London which examined the role of stressful life events in the onset of vitiligo in adults, which suggested that such patients endure a significantly high number of stressful events than controls $\left[{ }_{7}\right]$.

Several studies assessing stressful life events have been conducted and seem to confirm that stress may trigger the disease. The early onset of psoriasis ( $<40$ years) was associated more frequently with psychological factors, such as stress $[2,3,4,5,6]$.

\section{CORRESPONDENCE TO}

Kathem K Al-Rubiay. Assist. Professor . of Dermatology . Head Department of Dermatology . Basrah general hospital . College of Medicine, University of Basrah . PO .Box 289Ashar Basrah . Iraq. e-mail- kadhim1000@yahoo.com

\section{References}

1. Picardi A ,Abeni D .Stressful life events and skin diseases :disentangling evidence from myth .Psychother Psychosom..2001;70 (3): 118-36.

2. Naldi L, Peli L, Parazzini F, Carrel CF. Family history of psoriasis, stressful life events, and recent infectious disease are risk factors for a first episode of acute guttate psoriasis: results of a case-control study. J Am Acad Dermatol. 2001 Mar; 44(3); 433-8.

3. Devrimci Ozguven H, Kundakci TN , Kumbasar H,
Boyvat A.The depression, anxiety, life satisfaction and affective expression levels in psoriasis patients. J-Eur-AcadDermatol-Venereol. 2000 Jul; 14(4): 267-71

4. Raychaudhuri SP , Gross J . Psoriasis risk factors: role of lifestyle practices. Cutis. 2000 Nov; 66(5): 348-52

5. Mazzetti M, mozzetta A, Soavi GC , et al. Psoriasis , stress and psychiatry: Psychodynamic characteristics of stressors. Acta Derm Venerol Suppl (Stockh)1994;106:62-64 6. Kassab JY, Beer WE, Smith AE, Rowland Payne CME .Risk factors in early and late onset psoriasis : Family history ,stress, alcohol ,smoking and a life . Les Nouvelles Dermatologiques $1995: 14: 48-53$.

7. Papadopoulos L, Bor R, Legg C, HawkJL. Impact of life events on the onset of vitiligo in adults : preliminary evidence for psychological dimension in etiology .Clin Exp Dermatol $1998 ; 23$ (6) ;243-248 .

8. Gupta MA, Gupta AK,Wateel GN . Stress and alopecia areata :a psychodermatologic study . Acta Derm Venereol $1997: 77(4): 296-298$.

9. Garg A, Chren MM, Sands LP, Matsui MS, Marenus KD, Feingold KR, Elias PM . Psychological stress perturbs epidermal permeability barrier homeostasis: implications for the pathogenesis of stress-associated skin disorders. ArchDermatol. 2001 Jan; 137(1): 53-9

10. Misery L, Rousset H . La pelade est-elle une maladie psychosomatique? [Is alopecia areata a psychosomatic disease. Rev-Mcd-Interne, 2001 Mar;22(3): 274-9

11. Toyoda M, Makino T, Kagoura M, Morohashi M . Expression of neuropeptide-degrading enzymes in alopecia areata: an immunohistochemical study. Br-J-Dermatol. 2001 Jan; 144(1): 46-54

12. Kasarou-katsari A, Singh LK, Theoharides TC. Alopecia areata and affected skin CRH receptor upregulation induced by acute emotional stress . Dermatology .2001:203 (2):157-6L

13. Safavi KH, Lawrence RC . Making comparison :Moving from rates to inference. In : Wlliam HC, Strachan DP.The challenge of Dermatoepidemiology .Boco Raten ,New York :CRC press , 1997 :37-47. 


\section{Author Information}

Laith K. Qassim Al-Rubaiy, MBChB, MSc

King's College, St John's, Institute of Dermatology

Kathem K. Al-Rubiay, MSc ,PhD

Head, Department of Dermatology, Basrah General Hospital, College of Medicine, University of Basrah 